\title{
The willingness of patients to pay for intravenous patient- controlled analgesia in Korea
}

\author{
Hyungsun Lim, Duck-Hyoung Lee, Jeongwoo Lee, Young Jin Han, Huhn Choe, and Ji-Seon Son \\ Department of Anesthesiology and Pain Medicine, Chonbuk National University Medical School, Jeonju, Korea
}

Background: The use of intravenous patient-controlled analgesia (IV-PCA) has been increasing because it has advantages such as improved pain relief, greater patient satisfaction, and fewer postoperative complications. However, current research has not considered the patients' thoughts about IV-PCA's cost-effectiveness. The purpose of this study was to investigate the willingness to pay (WTP) for IV-PCA and the relationship between patients' characteristics and WTP in Korea.

Methods: We enrolled 400 adult patients who were scheduled for elective surgery. The patient was requested to indicate a series of predefined amounts of money (Korean won; 30,000/50,000/100,000/150,000/200,000/300,000/ $500,000)$. We also recorded patient characteristics, such as age, sex, type of surgery, IV-PCA history, education level, the person responsible for medical expenses, type of insurance, net annual income, and residential area. Three days after surgery, we asked about the degree of satisfaction and the WTP for IV-PCA.

Results: For IV-PCA, the median WTP was 100,000 won $(25-75 \%$; 50,000-200,000 won: US $\$ 1=$ W1078.04; July 19, 2011) before surgery. All patients' characteristics were not related to preoperative WTP for IV-PCA, whereas the increase in WTP after surgery showed a tendency correlated to higher IV-PCA satisfaction.

Conclusions: The median WTP was 100,000 won. The satisfaction of IV-PCA increased patients' WTP after surgery, but the WTP may be independent of patient characteristics in Korea. (Korean J Anesthesiol 2012; 62: 548-551)

Key Words: Patient controlled analgesia, Patient satisfaction, Willingness to pay.

\section{Introduction}

Patient-controlled analgesia (IV-PCA) is a delivery system that allows patients to self administer analgesics, which are predetermined by their physicians, to relieve pain. Since IV-
PCA was introduced in the early 1980s [1], it has become widely accepted for the management of postoperative pain. The use of IV-PCA has been increasing because of its proven advantages over conventional intramuscular injections [1]. These include improved pain relief, greater patient satisfaction, less

Received: August 10, 2011. Revised: September 20, 2011. Accepted: November 7, 2011.

Corresponding author: Ji-Seon Son, M.D., Department of Anesthesiology and Pain Medicine, Chonbuk National University Medical School, 634-18, Keumam-dong, Dukjin-gu, Jeonju 561-712, Korea. Tel: 82-63-250-1241, Fax: 82-63-250-1240, E-mail: sjs6803@chonbuk.ac.kr

(c) This is an open-access article distributed under the terms of the Creative Commons Attribution Non-Commercial License (http:// creativecommons.org/licenses/by-nc/3.0/), which permits unrestricted non-commercial use, distribution, and reproduction in any medium, provided the original work is properly cited. 
sedation, and fewer postoperative complications. Studies have also demonstrated patient satisfaction with acute pain service (APS) [2].

It is difficult to evaluate IV-PCA using a cost-utility analysis [3], because no universally accepted method of assigning monetary value to transient disutility such as postoperative pain is currently available. Willingness to pay (WTP) means the maximum amount of medical cost a patient is willing to pay to gain benefits or prevent any risks in medical care [4]. WTP is a methodological tool that seeks to estimate the capacity of certain social groups to pay to find out the hypothetical monetary value for programs and specific medical interventions and treatments.

The purpose of this study was to investigate the WTP for IVPCA and the relationship between characteristics of patients and WTP in Korea.

\section{Materials and Methods}

All participants were scheduled for elective surgery under general anesthesia. This trial included patients who were aged $18-80$ yrs to undergo various surgical procedures. To conduct regression tests, a power of 0.85 and an effect size of 0.15 were selected. Using these estimates, we decided to include 400 patients as the final sample size. After obtaining approval from the institutional ethical committees and written informed consent, we enrolled 400 adult patients. In the preoperative visit, patients were asked to complete a questionnaire on their WTP of IV-PCA (PCA pump, Ambix Anaplus ${ }^{\circledR}$, E-Wha Fresenius Kabi, Korea; drugs, fentanyl or morphine/ketorolac) for postoperative pain.

The patient was requested to indicate a series of predefined amounts of money (Korean won; 30,000/50,000/100,000/150,0 $00 / 200,000 / 300,000 / 500,000)$ that he or she would be willing to pay for reducing the pain as much as possible. We also recorded patient characteristics, such as age, sex, type of surgery (cancer or noncancer), IV-PCA history, education level (middle school graduation or below/high school graduation or dropout/ university student or above), the person responsible for medical expenses (self or spouse vs others), type of insurance (National Health Insurance vs Medicaid), net annual income (Korean won; $0 / 1-12,000,000 / 12,000,000-46,000,000 /$ more than $46,000,000$ ), and residential area (urban area vs rural area). Three days after the operation, we asked about the degree of satisfaction and the WTP for IV-PCA.

Data were reported as the median value $(25-75 \%)$ or mean \pm SD. To explore multivariate relationships, the chi-square test for preoperative WTP dependence on patient characteristics was performed, and then the Spearman rank order correlation test was performed. The following characteristics were considered as possible covariates for preoperative WTP: age, sex, type of surgery, IV-PCA history, education level, the person responsible for medical expenses, type of insurance, net annual income, and residential area. A linear regression test for dependence of individual WTP changes on IV-PCA experiences and degree of satisfaction were also performed. All statistical analyses were performed by SigmaStat for Windows version 3.1. $\mathrm{P}<0.05$ was considered to be statistically significant.

\section{Results}

Of the 400 participants, $400(100 \%)$ responded the WTP questionnaire, and complete preoperative and postoperative WTP data for IV-PCA were obtained. The patient's characteristics are shown in Table 1 . The mean age was $48.9 \pm 13.8$ years. Two groups, 0 won $(40.2 \%)$ and $12,000,000-46,000,000$ won $(39.8 \%)$ consisted of the majority of patients' net annual incomes. For IV-PCA, the number of patients who selected WTP 100,000 won before and after surgery was 120 (30\%) and 115 (28.85), respectively (Fig. 1). All patients' characteristics including age, sex, type of surgery, IV-PCA history, education

Table 1. Patient's Characteristics

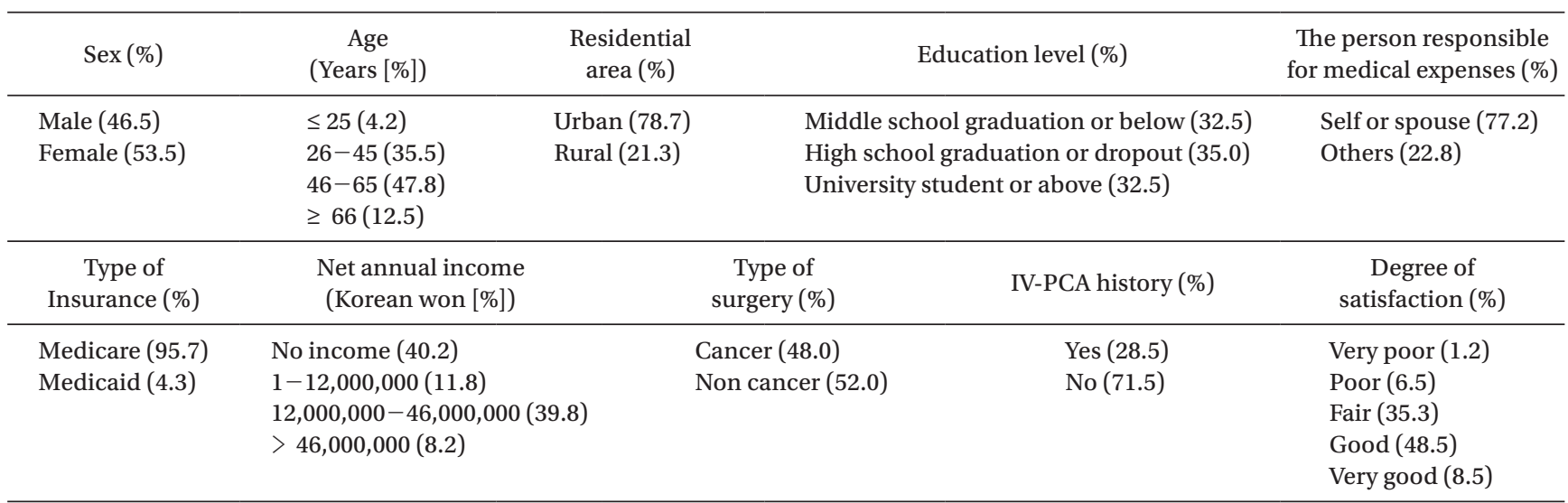




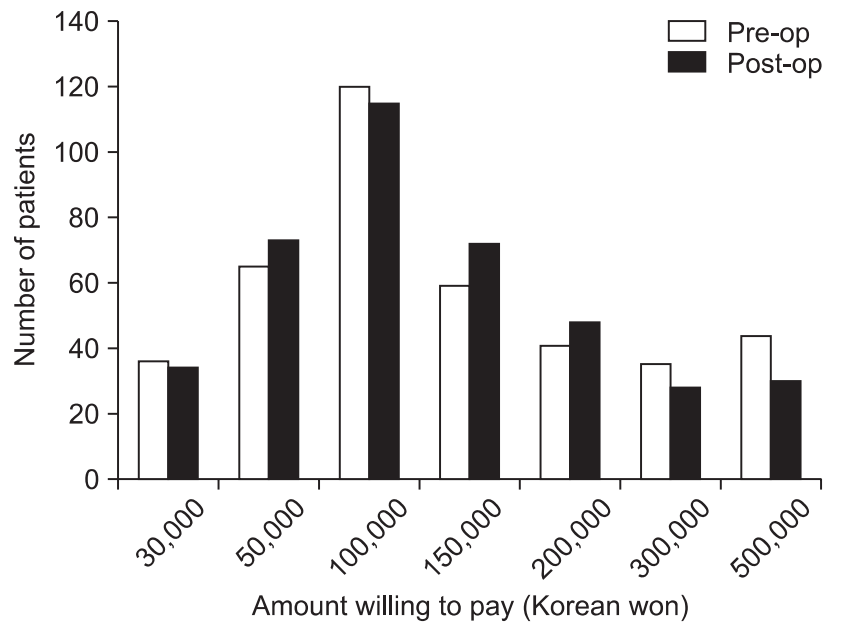

Fig. 1. Willingness to pay (WTP) for intravenous patient controlled analgesia. No significant difference was seen between the preoperative and postoperative WTP.

level, the person responsible for medical expenses, type of insurance, net annual income, and residential area were not related to preoperative WTP for IV-PCA. After surgery, $69.0 \%$ of the respondents were willing to pay the same amount of money for IV-PCA compared with the WTP before surgery, whereas $18.5 \%$ decreased their bid and $12.5 \%$ increased their bid. However, the increase in WTP after surgery had a tendency correlated with a higher degree of IV-PCA satisfaction (Fig. 2).

\section{Discussion}

IV-PCA has been shown in numerous studies to be beneficial for patients and for relieving pain, but no published studies have investigated cost-efficacy for IV-PCA. In general, the cost of IV-PCA has been decided without patient opinion in Korea. We measured patients' WTP for IV-PCA before and 3 days after surgery. This study showed that the preoperative median WTP for IV-PCA was 100,000 won (25-75\%; 50,000-200,000 won). It was not changed even after surgery. The national average cost for IV-PCA was about 120,000-300,000 won, although it varies depending on the specific PCA pump used and the amount or kind of drug administered.

In this study, it was found that increased WTP for IV-PCA had a tendency of correlation with higher levels of patient satisfaction. Those who had higher degrees of satisfaction showed a greater cost from their presurgical bid $[5,6]$. In the previous study to determine WTP for hip and knee joint replacement surgery, a significant correlation was found between WTP and degree of satisfaction [7]. Therefore, we believe that the degree of satisfaction is sufficient to reflect the degree of analgesic and side effects. We expected that patients who experienced great degrees of satisfaction for IV-PCA would increase their bid

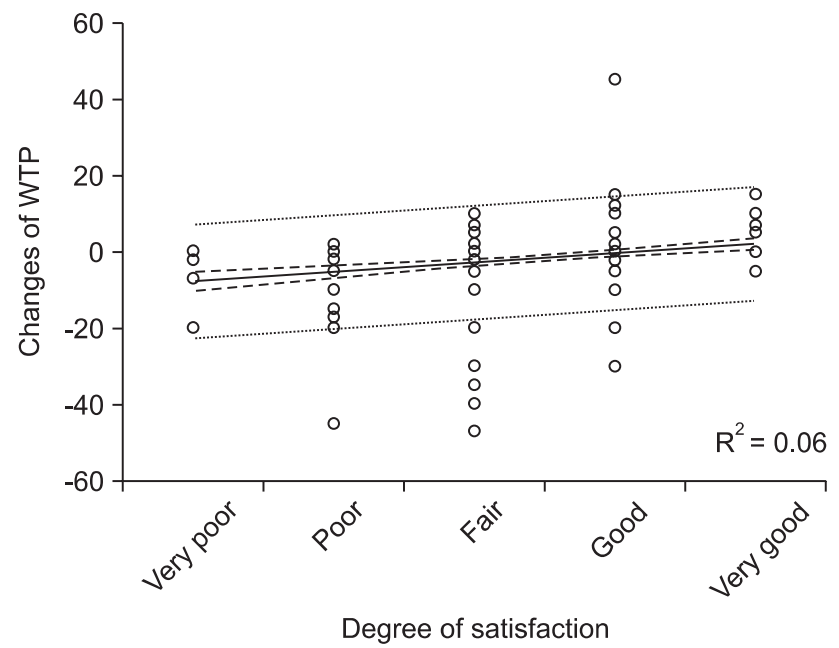

Fig. 2. Linear regression of the willingness to pay (WTP) between the changes in WTP and degree of satisfaction.

after IV-PCA. Although the increased WTP for IV-PCA have a tendency towards higher degrees of satisfaction, the median WTP was not changed before and after surgery.

Previous studies confirm the relationship between income and WTP for postoperative nausea and vomiting (PONV) [6,8-11], but the influence of net annual incomes on WTP could not be confirmed in our study. Other studies showed that income was not significantly correlated to WTP for total knee replacement (TKR) or PONV [7,12]. This result may be due to the fact that almost $70 \%$ of the group were pensioners and had limited incomes. In our study, net annual incomes of $43.3 \%$ of participants were 0 . Although we were not able to confirm that income is significantly correlated to WTP for IV-PCA, patients who earned higher incomes tended to be have a greater WTP without statistical significance.

We also assumed that the estimates for WTP were highly dependent on age, type of insurance, education level, and IV-PCA history. A previous study found that WTP for TKR was correlated with age [7], showing that older respondents undergoing TKR were more likely to be willing to pay. The reason might be that patients in the study suffered from arthritic pain for a long time. However, a significant correlation was not found between WTP and age in our study. Other previous studies found that WTP was correlated with type of insurance [13] or education level $[11,14]$. Although health care is comprehensive in Korea with almost every therapeutic treatment provided with little cost to patients, the cost of IV-PCA is not covered by the current health care system. A significant correlation between WTP and type of insurance was not found in our study. Education level of the patient was not a predictor for WTP, but patients with higher education levels tended to have more WTP without statistical significance. IV-PCA history 
was not a predictor for WTP, either.

Our study has several limitations. First, the presentation skills of data collectors can influence the results, which can be introduced with a facilitator bias. Although instructions and scripts were provided to the facilitators, our results still have a facilitator bias because the presentation was given by multiple facilitators. Second, the respondents in this study did pay the full cost of their IV-PCA because National Health Insurance does not cover the cost of IV-PCA in Korea. Therefore, our results may not be generalized to other hospitals in other provinces or cities.

In conclusion, the median WTP for IV-PCA was 100,000 won. The increased WTP for IV-PCA showed a tendency of correlation with higher degrees of patient satisfaction after surgery, but the WTP value may be independent of age, sex, IV-PCA history, education level, the person responsible for medical expenses, type of insurance, net annual income, and residential area.

\section{References}

1. Bollish SJ, Collins CL, Kirking DM, Bartlett RH. Efficacy of patientcontrolled versus conventional analgesia for postoperative pain. Clin Pharm 1985; 4: 48-52.

2. Comley AL, DeMeyer E. Assessing patient satisfaction with pain management through a continuous quality improvement effort. J Pain Symptom Manage 2001; 21: 27-40.

3. Robinson R. Economic evaluation and health care. What does it mean? BMJ 1993; 307: 670-3.

4. Ko S. Applying the concept of willingness to pay in the anesthetic management. Korean J Anesthesiol 2009; 57: 149-50.

5. Badner NH, Komar WE, Craen RA. Patient attitudes regarding pca and associated costs. Can J Anaesth 1997; 44: 255-8.

6. Pinto SL, Holiday-Goodman M, Black CD, Lesch D. Identifying factors that affect patients' willingness to pay for inhaled insulin. Res Social Adm Pharm 2009; 5: 253-61.

7. Cross MJ, March LM, Lapsley HM, Tribe KL, Brnabic AJ, Courtenay BG, et al. Determinants of willingness to pay for hip and knee joint replacement surgery for osteoarthritis. Rheumatology (Oxford) 2000; 39: 1242-8.

8. Gan T, Sloan F, Dear Gde L, El-Moalem HE, Lubarsky DA. How much are patients willing to pay to avoid postoperative nausea and vomiting? Anesth Analg 2001; 92: 393-400.

9. van den Bosch JE, Bonsel GJ, Moons KG, Kalkman CJ. Effect of postoperative experiences on willingness to pay to avoid postoperative pain, nausea, and vomiting. Anesthesiology 2006; 104: 1033-9.

10. Chung S, Kim KO, Lee JH, Lee KJ. How much are patients willing to pay for prevention of postoperative nausea and vomiting? Korean J Anesthesiol 2009; 57: 151-4.

11. Nowakowska D, Guertin JR, Liu A, Abrahamowicz M, Lelorier J, Lesperance F, et al. Analysis of willingness to pay for implantable cardioverter-defibrillator therapy. Am J Cardiol 2011; 107: 423-7.

12. Kerger H, Turan A, Kredel M, Stuckert U, Alsip N, Gan TJ, et al. Patients' willingness to pay for anti-emetic treatment. Acta Anaesthesiol Scand 2007; 51: 38-43.

13. Harris B, Nxumalo N, Ataguba JE, Govender V, Chersich M, Goudge J. Social solidarity and civil servants' willingness for financial crosssubsidization in South Africa: implication for health financing reform. J Public Health Policy 2011; 32 Suppl 1: S162-83.

14. Petersen KD, Gyrd-Hansen D, Linneberg A, Dahl R, Larsen JN, Lowenstein $\mathrm{H}$, et al. Willingness to pay for allergy-vaccination among Danish patients with respiratory allergy. Int J Technol Assess Health Care 2010; 26: 20-9. 